\title{
Spontaneous Periodic Hynothermia with Reduced Basal Temperature in a Patient of Hynoxic Ischemic Encephalopathy Following Surgery for Gervical Spine Injury
}

Hitesh Dawar, Harvinder S Chhabra

Department of Orthopedics, Indian Spinal Injuries Center, Vasant Kunj, New Delhi, India.

\section{Abstract:}

A 45 years male presented with C5-C6 flexion-distraction injury with quadriplegia (ASIA-A), and after reduction, was operated for anterior stabilization and fusion. Twenty two hours after uneventful surgery, patient sustained hypoxic-ischemic-encephalopathy in an episode of seizure. Following this, he had multiple episodes of hypothermia $\left(92^{\circ} \mathrm{F}\right)$ with bradycardia and desaturation, responding well to rewarming measures. Episodes were infrequent initially, subsequently became frequent, with basal readjustment of core temperature to $94^{\circ} \mathrm{F}$, following which bradycardia and desaturation settled. Such instance of basal readjustment of core temperature in a cervical injured patient with ischemic brain injury has never been reported.

Key words: Brain Injuries, Hypothermia, Hypoxia-Ischemia, Quadriplegia, Rewarming, Temperature.

\section{Introduction}

Spontaneous periodic episodes of hypothermia along with reduced basal temperature in a patient of cervical spine injury complicated by diffuse ischemic injury to the brain following surgery is an unheard of a case scenario. We hereby report such a case, and examine possible causes for this anomaly, and discuss its management.

\section{Case Report}

A 45 years old male, with no previous medical or surgical history, was admitted in our hospital following a road accident in which he sustained C5-C6 flexion-distraction injury with quadriplegia (ASIA-A) [Fig.1]. After reduction, he was operated wherein anterior C5-C6 discectomy, bone grafting with plating was done.

Following surgery patient had an uneventful reversal from anaesthesia, and was kept electively intubated and ventilated as per institutional protocol. Patient was hemodynamically stable initially, but had seizure during which he developed desaturation, bradycardia and unconsciousness. He was resuscitated and stabilized hemodynamically and gained consciousness but response to stimuli was very limited. Following investigations, he was diagnosed to have sustained a diffuse hypoxic ischemic injury to the brain. MRI showed bilateral diffuse hyper-intensities in caudate and lentiform

\section{Corresponding Author: Dr. Hitesh Dawar}

Email: hiteshdawar@gmail.com

Received: June 11, 2016 | Accepted: August 23, 2016 | Published Online: October 20, 2016

This is an Open Access article distributed under the terms of the Creative Commons Attribution License (creativecommons.org/licenses/by/3.0)

Conflict of interest: None declared | Source of funding: Nil | DOl: http://dx.doi.org/10.17659/01.2016.0120 
nuclei on T2, FLAIR and DWI images suggesting of hypoxic changes [Fig.2].

He was managed conservatively with neuroprotective and antiepileptic medications, with requisite hemodynamic support. Over time he was gradually weaned off the hemodynamic and ventilatory support, and continued to sustain himself. Patient had multiple episodes of hypothermia (upto $92^{\circ} \mathrm{F}$, rectal temperature) with bradycardia and desaturation; always responding well to rewarming measures, which consisted of physical rewarming and administration of warm intravenous fluids. He was monitored closely and was maintained with oxygen through mask and rewarming measures during such episodes. These episodes were infrequent initially (once in 3 days), subsequently became frequent (2-3 times in a day), with basal readjustment of the core temperature to $94^{\circ} \mathrm{F}$ gradually [Fig.3] following which episodes of bradycardia and desaturation gradually settled. Blood and other investigations apart from MRI were normal throughout.

Patient was clinically stable 32 weeks postoperatively with reduced basal temperature, with no further episode of bradycardia or desaturation for at-least 6 weeks, when he discharged for domiciliary care.

\section{Discussion}

Thermoregulation in a human body to a temperature around $37^{\circ} \mathrm{C}$ occurs by a complex mechanism $[1,2]$. The regulatory apparatus consists of peripheral thermoreceptors that relay afferent signals to central integrating mechanisms. Central and peripheral thermal information are hypothesized to be integrated at multiple sites in the CNS, with a facilitatory or an inhibitory effect. Integrators compare the information with that from internal thermosensitive cells and if necessary activate behavioural and autonomic mechanisms via efferent channels $[3,4]$.

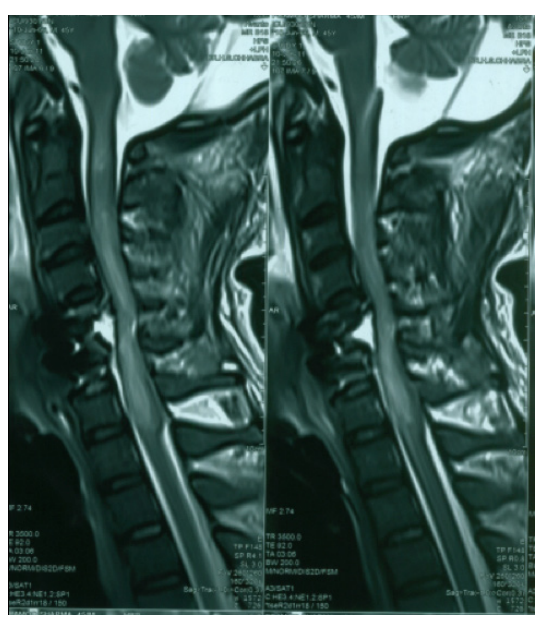

Fig.1: MRI image of the patient showing cervical injury $\mathrm{C} 5-\mathrm{C} 6$.

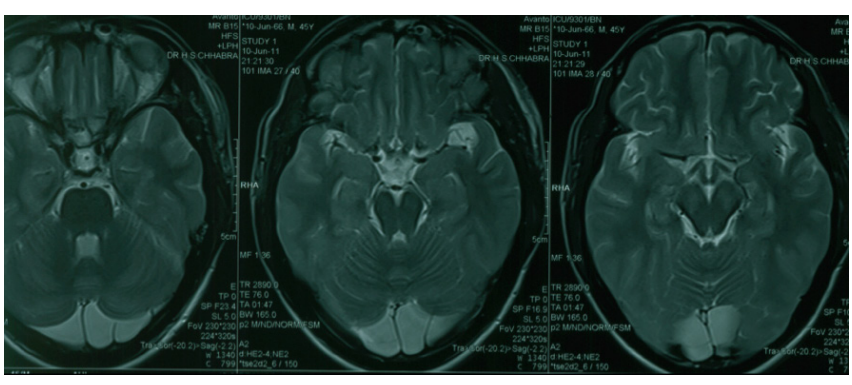

Fig.2: MRI brain showing bilateral diffuse hyper-intensities in caudate and lentiform nuclei suggesting of hypoxic changes.

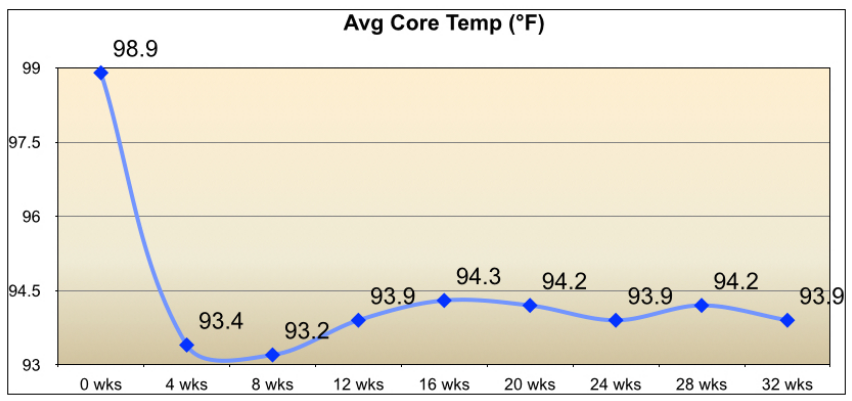

Fig.3: Average core temperature chart of the patient (degree fahrenheit). 
Thermoregulation occurs at several levels or centers, the hypothalamus, including the preoptic area, the anterior and posterior hypothalamus, brainstem, and cervical cord. The hypothalamus acts as the chief integrator which coordinates the activity of the other centers. Discrete lesions of the anterior hypothalamus can lead to either hyperthermia or hypothermia, whereas lesions in the posterior hypothalamic nucleus tend to produce hypothermia. Hypothermia may also occur when there is damage to the reflex thermoregulatory pathways traversing the brainstem or spinal cord [5-11].

It is well known that temperature regulation is affected in cervical injured patients. Reasons suggested for the mechanism of this phenomenon are damage to the connections between the temperature regulating centre in the hypothalamus and the sympathetic outflow from the cord motor tract damage prevents shivering except in the nonparalysed muscles [10].

In our patient, the hemodynamic status was well balanced initially after the trauma, during the surgery and after reversal from anaesthesia. But following seizure, patient had multiple episodes of hypothermia, the duration and frequency of which kept on increasing over days and weeks; these episodes were accompanied with bradycardia and desaturation, which were severe initially. With time, the basal core temperature failed to return to normal sometimes between these episodes, with less severe bradycardia and desaturation. Gradually the basal temperature readjusted to about a lower level of $94^{\circ} \mathrm{F}$, with no other clinical manifestation.

White etal. also reported an altered lowered thermoregulatory set point in a patient with chronic hypothermia while describing a series of patients of multiple sclerosis with episodic hypothermia [12]. They described presence of hypothalamic lesions on autopsy after the death in the same patient, even though no lesions were reported on imaging [12].
In our patient, MRI showed bilateral diffuse hyperintensities in caudate and lentiform nuclei suggesting of hypoxic changes, though no hypothalamic lesions were identified.

Thrombocytopenia as seen in patients with hypothermia and multiple sclerosis has been reported in other cases of accidental and spontaneous hypothermia, though we found no such abnormality in our patient $[12,13]$. Literature supports our belief that rapid rewarming and conservative management is mainly required to manage the hypothermia in such cases [8-13] though there are no recommendations available for management of chronic hypothermia or resetting of thermoregulation set point.

\section{Conclusion}

Autonomic dysregulation is known in cervical injury and could cause episodes of recurrent hypothermia, prolonged duration of the same might result in resetting of the thermostat. Our patient was asymptomatic, even with a basal core body temperature hovering around $94^{\circ} \mathrm{F}$ without any active intervention. This is an unusual case of basal readjustment of temperature to a lower level in a cervical injured patient with ischemic head injury, never reported till date to our knowledge.

\section{References}

1. Maclean D, Emslie-Smith D. Regulation of body temperature. In: Accidental hypothermia. Oxford: Blackwell, 1977:14-56.

2. Hensel $H$. Principles of temperature regulation. In: Thermoreception and temperature regulation. London: Academic Press, 1981:517. (Monographs of the Physiological Society No 38).

3. Satinoff E. Neural organization and evolution of temperature regulation in mammals. Science $1978 ; 201: 16-22$. 
4. Hensel H. Central thermoregulatory connections. In: Thermoreception and temperature regulation. London: Academic Press, 1981:13954. (Monographs of the Physiological Society No 38).

5. Upton JM, Dwyer PE, Fossler DE. Effects of brainstem lesions on temperature regulation in hot and cold environments. Am J Physiol. 1974;226:1356-1357.

6. Gordon CJ, Heath JE. Integration and central processing in temperature regulation. Ann Rev Physiol. 1986;48:595-612.

7. Hinkel P, Schroder-Rosenstock K. Responses of pontine units to skin-temperature in the guinea pig. Jf Physiol 1981;314:189-194.

8. D'Anglejan Chatillon J, Broussier PM, Boukobza $M$, Pannier I. Hypothermie au cours d'un syndrome de Gayet-Wemicke et myelinoysee centropontine infraclinique. La presse medicale. 1988; 17:1858.
9. Gaymard G, Cambon H, Dormont D, Richard A, Derovesne C. Hypothermia in a mesodiencephalic haematoma. J Neurol Neurosurg Psychiatry. 1990;53:1014-1017.

10. Pledger HG. Disorders of temperature regulation in acute traumatic tetraplegia. J7 Bone Joint Surg. 1962;44:1 10-113.

11. Menard MR, Hahn G. Acute and chronic hypothermia in a man with spinal cord injury: environmental and pharmacologic causes. Arch Phys Med Rehabil. 1991;72:421-424.

12. White KD, Scoones DJ, Newman PK. Hypothermia in multiple sclerosis. Journal of Neurology, Neurosurgery, and Psychiatry. 1996;61:369375.

13. Ghawche F, Destee A. Hypothermie et sclerose en plaques, un cas avec trois episodes d'hypothermie transitoire. Rev Neurol (Paris). 90;1 146:767-769. 